\title{
Leukemia Inhibitory Factor Is an Anti-Inflammatory and Analgesic Cytokine
}

\author{
Lisa R. Banner, ${ }^{1}$ Paul H. Patterson, ${ }^{1}$ Andrew Allchorne, ${ }^{2}$ Steve Poole,${ }^{3}$ and Clifford J. Woolf ${ }^{2,4}$ \\ ${ }^{1}$ Division of Biology, California Institute of Technology, Pasadena, California 91125, 2Department of Anatomy and \\ Developmental Biology, University College London, London WC1E 6BT, England, ${ }^{3}$ Division of Endocrinology, National \\ Institute for Biological Standards and Control, Herts EN6 3QG, England, and ${ }^{4}$ Department of Anesthesiology, \\ Massachusetts General Hospital and Harvard Medical School, Charlestown, Massachusetts 02129
}

The mRNA for leukemia inhibitory factor (LIF), a neuroimmune signaling molecule, is elevated during skin inflammation produced by intraplantar injection of complete Freund's adjuvant (CFA). Moreover, although LIF knock-out mice display normal sensitivity to cutaneous mechanical and thermal stimulation compared with wild-type mice, the degree of CFA-induced inflammation in mice lacking LIF is enhanced in spatial extent, amplitude, cellular infiltrate, and interleukin (IL)-1 $\beta$ and nerve growth factor (NGF) expression. Conversely, local injection of low doses of recombinant LIF diminishes mechanical and thermal hypersensitivity as well as the IL-1 $\beta$ and NGF expression induced by CFA. These data show that upregulation of LIF during peripheral inflammation serves a key, early antiinflammatory role and that exogenous LIF can reduce inflammatory hyperalgesia.

Key words: pain; inflammation; edema; hyperalgesia; primary sensory neuron; analgesia
Leukemia inhibitory factor (LIF) is a neuropoietic cytokine involved in both the neural and immune responses to injury. Its levels are increased in a variety of animal and human inflammatory conditions (Perry et al., 1987; Alexander et al., 1994; Brown et al., 1994; Ulich et al., 1994; Benigni et al., 1996; Heyman et al., 1996; Weinhold and Ruther, 1997). Administration of LIF can suppress inflammatory signs in some cases (Alexander et al., 1994), for instance after intratracheal lipopolysaccharide-induced inflammation (Ulich et al., 1994). LIF also increases corticosterone levels via the hypothalamo-pituitary-adrenal axis (Baba et al., 1998). Other evidence suggests, however, that it can also act as a proinflammatory cytokine. Exogenously added LIF induces acute phase protein expression (Ryffel, 1993; Mehlen et al., 1997) and stimulates the production of proinflammatory cytokines and monocyte chemoattractants (Alexander et al., 1994; Paglia et al., 1996; Shimon et al., 1997). Moreover, passive immunization against LIF protects mice against the lethal effects of endotoxin and blocks endotoxin-induced increases in serum interleukin-1 (IL-1) and IL-6 (Block et al., 1993), and injection of high concentrations of LIF into skin or joints can induce swelling and leukocyte invasion (Carroll et al., 1995; McKenzie et al., 1996).

In the nervous system, LIF mRNA levels dramatically increase soon after injury (Patterson, 1994; Kurek et al., 1996; Banner et al., 1997), and experiments with LIF null mutant mice demonstrate that LIF is required for some of the striking changes in neuronal gene expression that are characteristic of the injury

\footnotetext{
Received Nov. 20, 1997; revised April 10, 1998; accepted April 28, 1998.

This work was supported by the Medical Research Council (C.J.W.), the Wellcome Trust (C.J.W.), the Human Frontiers Science Program (C.J.W.), the National Institutes of Health National Research Service Award (L.R.B.), and the National Institute of Neurological Diseases and Stroke (P.H.P.).

Correspondence should be addressed to Dr. Clifford J. Woolf, Neural Plasticity Research Group, Department of Anesthesiology and Critical Care, Massachusetts General Hospital and Harvard Medical School, Building 149, 13th Street, Charlestown, MA 02129

Copyright (ㄷ) 1998 Society for Neuroscience $\quad 0270-6474 / 98 / 185456-07 \$ 05.00 / 0$
}

response (Rao et al., 1993; Corness et al., 1996; Sun and Zigmond, 1996). Lack of LIF can also lead to premature neuronal death (Sendtner et al., 1996) and a diminished rate of immune cell influx after peripheral nerve injury (Patterson et al., 1997). LIF and its receptors (gp130) are abundantly expressed in pituitary cells, and LIF acts in a paracrine manner to regulate adrenocorticotrophin and growth hormone release (Lotz et al., 1992; Waring et al., 1992; Szepietowski et al., 1997).

Thus, although LIF appears to be a central regulator of inflammatory events and their interaction with the nervous system, there is contradictory evidence whether this cytokine is proinflammatory or anti-inflammatory. To help clarify these issues and to further probe interactions between the nervous and immune systems during the injury response, we have used both LIF knock-out mice and LIF injections in a well characterized, local inflammatory pain model, the intraplantar injection of complete Freund's adjuvant (CFA) (Stein et al., 1988; Woolf et al., 1994, 1996; Safieh-Garabedian et al., 1995).

\section{MATERIALS AND METHODS}

All animal procedures conformed with the requirements of either the British Home Office Animal Licensing Inspectorate or the Caltech Research Animal Care Committee.

Inflammation in rats. Experiments were performed on adult male Sprague Dawley rats (200-250 gm). A unilateral, acute inflammatory lesion was produced by an injection into the plantar surface of the hindpaw, under halothane anesthesia (2\%), of $100 \mu \mathrm{l}$ of CFA [1 mg/ml Mycobacterium tuberculosis (H37Ra, ATCC 25177, in $0.85 \mathrm{ml}$ of paraffin oil and $0.15 \mathrm{ml}$ of mannide monooleate; Sigma, St. Louis, MO)]. Thermal and mechanical sensitivity were tested as described previously in detail (Safieh-Garabedian et al., 1995; Woolf et al., 1996). Foot withdrawal on exposure to a hot plate $\left(50^{\circ} \mathrm{C}\right)$ was used as an index of thermal sensitivity, whereas the mechanical threshold for eliciting a flexion withdrawal response was measured in grams, using calibrated monofilament Von Frey hairs (4.1-72 gm) as an index of mechanical sensitivity. Von Frey hairs were applied three times $(0.5 \mathrm{~Hz})$ at a right angle to the dorsum of the foot in ascending order of force until a withdrawal response was elicited on all three occasions. The order was then reversed, and lowerforce hairs were applied. The threshold was defined as the lowest force 
hair that elicited a clear withdrawal response on each of the three applications. Paw diameters in millimeters were measured under terminal pentobarbital anesthesia $(500 \mathrm{mg} / \mathrm{kg}$, i.p.) using a micrometer gauge (Stanley) applied across the dorsoventral plane of the hindpaw in its midposition.

LIF null mutant mice. LIF-deficient mutant mice (Stewart et al., 1992) were maintained by mating within the original colony of the mutant strain or by back-crossing with the C57Bl6 parental strain. All of the data reported here on mutant mice come from the former matings. Null mutants were produced by mating heterozygotes or by mating null males with heterozygote females. Nulls, heterozygotes, and wild-type (WT) mice were compared as littermates. A PCR-based method was used to determine the genotype of the mice. Genomic DNA was isolated from tail biopsies and subjected to PCR amplification. Two DNA fragments were coamplified: a 192 bp LIF gene fragment and a 541 bp neomycin gene fragment. LIF WT mice contained only the LIF product (192 bp), the heterozygotes had both bands (192 and $541 \mathrm{bp}$ ), and the LIF-deficient mice had only the larger fragment (541 bp).

Inflammation in mice. CFA induced inflammation in LIF $-/-$ and $+/+$ mice was produced as above, except that only $20 \mu \mathrm{l}$ of CFA was injected. Mechanical sensitivity was measured using Von Frey hairs as above, and paw diameter was also measured as described above. The CFA injections into the mice were all made together at one sitting, and the tester was blinded to the genotype of the animals. Inflammatory cell infiltration was studied in paraformaldehyde-fixed, hematoxylin and eosin-stained skin sections. Cell types were quantified by counting neutrophils and mast cells from three animals of each genotype (three sections per animal). The number of polymorphonuclear neutrophils was determined by counting the number of cells with multilobed nuclei in a representative $100-\mu \mathrm{m}$-wide band from the outer edge of the epidermis to the inner edge of the dermis. Only cells with more than one nucleus per cell were taken as positive. Mast cells were quantified in a similar manner, counting only those cells that were of the appropriate size and contained obvious granules.

LIF mRNA measurements. Rat footpad skin was removed under deep terminal pentobarbital anesthesia, and total RNA was extracted by the acid-phenol method and RNase protection performed as described previously (Banner and Patterson, 1994). The intensity of the radioactive signal emitted by the LIF-protected fragment was compared with the glyceraldehyde phosphate dehydrogenase (GAPDH)-protected fragment as an internal control for the steady-state amount of RNA, and the values were expressed in arbitrary units. GAPDH mRNA was found not to change with injury.

IL-1 and NGF measurements. Under deep terminal pentobarbital anesthesia, samples of either rat or mouse hindpaw skin, sciatic nerve, and L4 and L5 dorsal root ganglia were dissected, weighed, and frozen on dry ice. The tissue was used for determination of IL-1 $\beta$ and NGF by ELISA, as described previously (Safieh-Garabedian et al., 1995). Results are expressed as nanograms per hindpaw to account for changes in weight of inflamed skin.

LIF administration. Recombinant human LIF (Preparation 93/562, 1 $\mu \mathrm{g}=10,000 \mathrm{U}$; National Institute for Biological Standards and Control) was dissolved in saline at concentrations of 100 or $1000 \mathrm{ng} / \mathrm{ml}$ and injected into the rat hindpaw under halothane anesthesia $(2 \%)$ in a volume of $100 \mu \mathrm{l}$.

Statistical analysis. All results are presented as mean \pm SEM. Differences were calculated using Student's or Welch's $t$ test, ANOVA followed by Dunnet's multiple-comparison test, or the Mann-Whitney $U$ test, where appropriate.

\section{RESULTS}

\section{LIF mRNA levels in inflamed skin}

Six hours after induction of acute inflammation in the rat hindpaw by intraplantar injection of CFA, LIF mRNA levels were measured by an RNase protection assay and expressed as a ratio with GAPDH mRNA. This cytokine is elevated in the inflamed skin at this time $(4.1 \pm 1.8$ ipsilateral, $2.8 \pm 1.1$ contralateral, from naive levels of 1.0; LIF/GAPDH \pm SEM; $n=4$ ), with a trend to a further increase at $48 \mathrm{hr}(5.7 \pm 2.1$ ipsilateral, $1.4 \pm 0.3$ contralateral). A smaller, bilateral change occurred in the sciatic nerve $(2.4 \pm 1.1$ ipsilateral, $1.9 \pm 0.4$ contralateral, from naive levels of 1.0; LIF/GAPDH $\pm \mathrm{SEM} ; n=4 ; 6 \mathrm{hr}$ after CFA).

\section{Inflammation in LIF knock-out mice}

To directly test whether LIF is required for either the development of or recovery from inflammation, we studied the effects of CFA injection in LIF knock-out mice. The general appearance and behavior of WT and LIF knock-out mice are quite similar, although the latter are slightly smaller (Stewart et al., 1992). There is, however, a very significant difference in the response of the two strains to CFA injection. Four hours after CFA administration, the hindpaws in the mutant mice were swollen on the entire dorsal and plantar surfaces, which differed with the degree
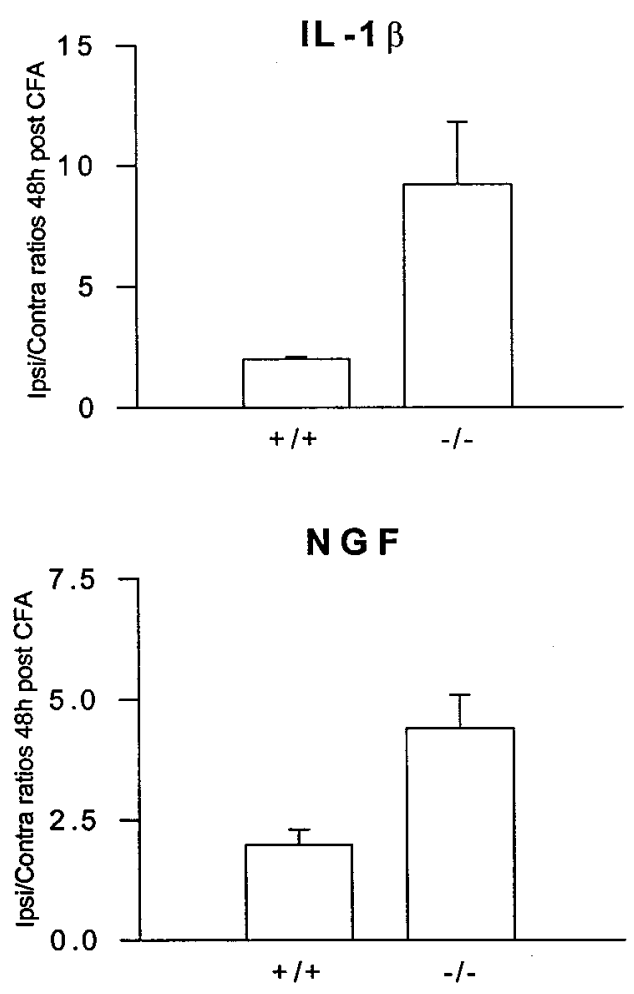

Swelling

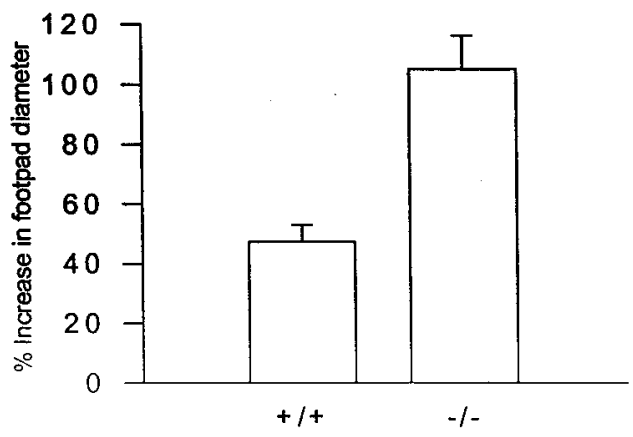

Figure 1. Several measures of inflammation after injection of CFA are strongly enhanced in LIF knock-out mice. The LIF knock-out mice display a significantly greater elevation of both IL-1 $\beta$ and NGF than the WT mice $(p<0.05 ; n=5)$. IL- $1 \beta$ and NGF levels measured by ELISA are expressed as the ratio of the values obtained from the ipsilateral paw over the contralateral paw. Both WT $(+/+)$ and LIF null mutant $(-/-)$ mice were examined $48 \mathrm{hr}$ after CFA injection in the ipsilateral paw. Swelling is expressed as the change in the dorsoventral paw diameter value from preinflamed levels in WT $(+/+)$ and LIF $(-/-)$ null mutant mice. The percent increase in the mutant mouse was substantially greater ( $p<0.01$, Mann-Whitney $U$ test) than in the WT mice. $n=12$ for naive and WT; $n=6$ for all other groups. 

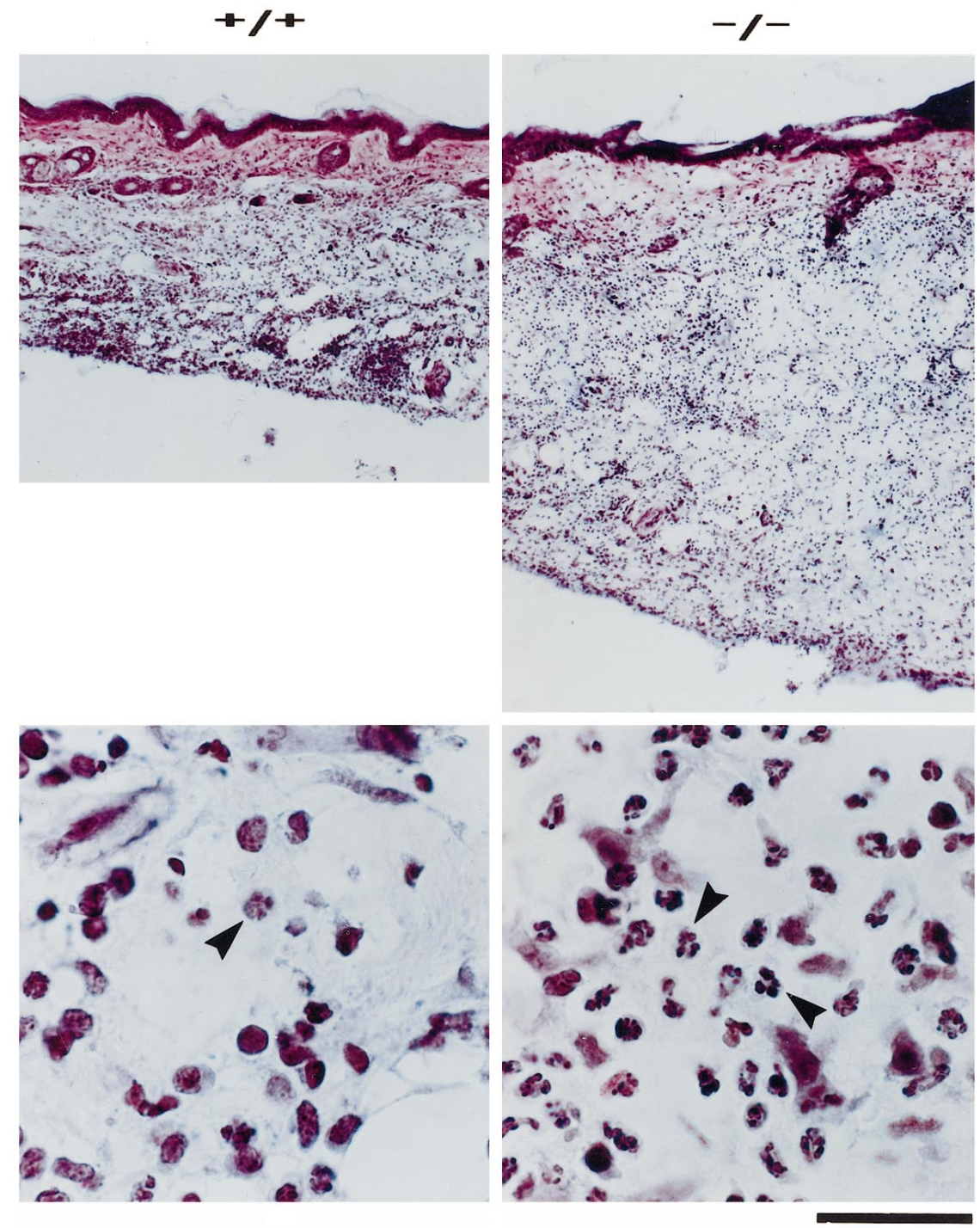

Figure 2. Adjuvant-induced inflammation produces a greater immune cell infiltration in LIF mutant $(-/-)$ than in WT $(+/+)$ mice. Hematoxylin and eosin staining of the footpad skin, $48 \mathrm{hr}$ after CFA injection, reveals a much thicker dermis (top) in the $-/-$ compared with $+/+$ mice. Bottom panels reveal that this difference is attributable to more polymorphonuclear neutrophils (arrowhead) in the dermis of $-/-$ compared with $+/+$ mice. Scale bar: top panels; $200 \mu \mathrm{m}$; bottom panels, $20 \mu \mathrm{m}$.

of swelling in WT mice, which at this time point was restricted to the site of the injection. At 24 and $48 \mathrm{hr}$ the swelling spread past the ankle and up the calf, and the entire plantar and dorsal skin of the foot was under marked tension and edematous. In WT littermates at these time points, inflammation was limited to the hindpaw, and even here it was much less prominent than in the $-/-$ mice. The difference in dorsoventral paw diameter at $48 \mathrm{hr}$ after CFA injection was quantified for the two strains and is presented in Figure 1. The mean percentage increase in paw diameter is more than twice as great in the LIF knock-out mice compared with WT mice $(p<0.01)$. Because the degree of swelling in the $-/-$ mice was associated with a marked changes in the tension, compliance, fluid content, and thickness of the skin, a meaningful comparison of mechanical and thermal sensitivity between WT and -/- mice was not possible.

Another assay for inflammation involves quantification of cytokines and growth factors that are elevated under a variety of inflammatory conditions (Woolf et al., 1994, 1996; SafiehGarabedian et al., 1995). We found that CFA injection induced a twofold elevation in IL- $1 \beta$ at $24 \mathrm{hr}$ in WT mice (from naive levels of $564 \pm 27 \mathrm{pg} /$ hindpaw to $1068 \pm 63 \mathrm{pg}$ /ipsilateral hindpaw and $526 \pm 21 \mathrm{pg} /$ contralateral hindpaw; $n=5$ ). In LIF knock-out mice, however, the IL- $1 \beta$ levels at $48 \mathrm{hr}$ after CFA were $1712 \pm$
$364 \mathrm{pg} /$ ipsilateral hindpaw and $226 \pm 53 \mathrm{pg} / \mathrm{contralateral} \mathrm{hind-}$ paw; $(n=5)$. When the data are expressed as a ratio of the levels in the inflamed (ipsilateral) to noninflamed (contralateral) hindpaws at $48 \mathrm{hr}$, CFA induces a twofold rise in IL-1 $\beta$ in the WT mice and a ninefold rise in the mutant mice (Fig. 1). A similar difference was detected for NGF levels in the hindpaw, with a significantly greater ratio in mutant versus WT animals (Fig. 1). At $48 \mathrm{hr}$, NGF levels in WT mice were $94.6 \pm 10 \mathrm{pg}$ /ipsilateral hindpaw and $40.8 \pm 12.8 \mathrm{pg} /$ contralateral hindpaw $(n=5)$, whereas in mutant mice the levels were $186 \pm 46 \mathrm{pg} /$ ipsilateral hindpaw and $49.3 \pm 21 \mathrm{pg} /$ contralateral hindpaw; $(n=5)$.

Analysis of the thickness and cellular infiltrates in WT and LIF mutant mice reinforced these findings. Staining of skin sections $48 \mathrm{hr}$ after CFA revealed not only a much thicker dermis in the mutants, but many more densely stained neutrophils (Fig. 2). This difference was quantified by counting cells in nine sections from three animals of each genotype. The LIF mutant mice had 4.8-fold more neutrophils in the inflamed dermis than WT littermates $(+/+, 40.2 \pm 7.1 ;-/-, 190.0 \pm 15.1 ; n=9)$. When expressed as neutrophil density (per $100 \mu \mathrm{m}^{2}$ ), the mutants had more than twice as many cells as the WT mice $(+/+, 8.6 \pm 0.2$; $-/-, 20.8 \pm 1.5 ; p<0.005)$. The mutants also had greater than twofold more mast cells than the WT mice. 


\section{Mechanical Sensitivity}
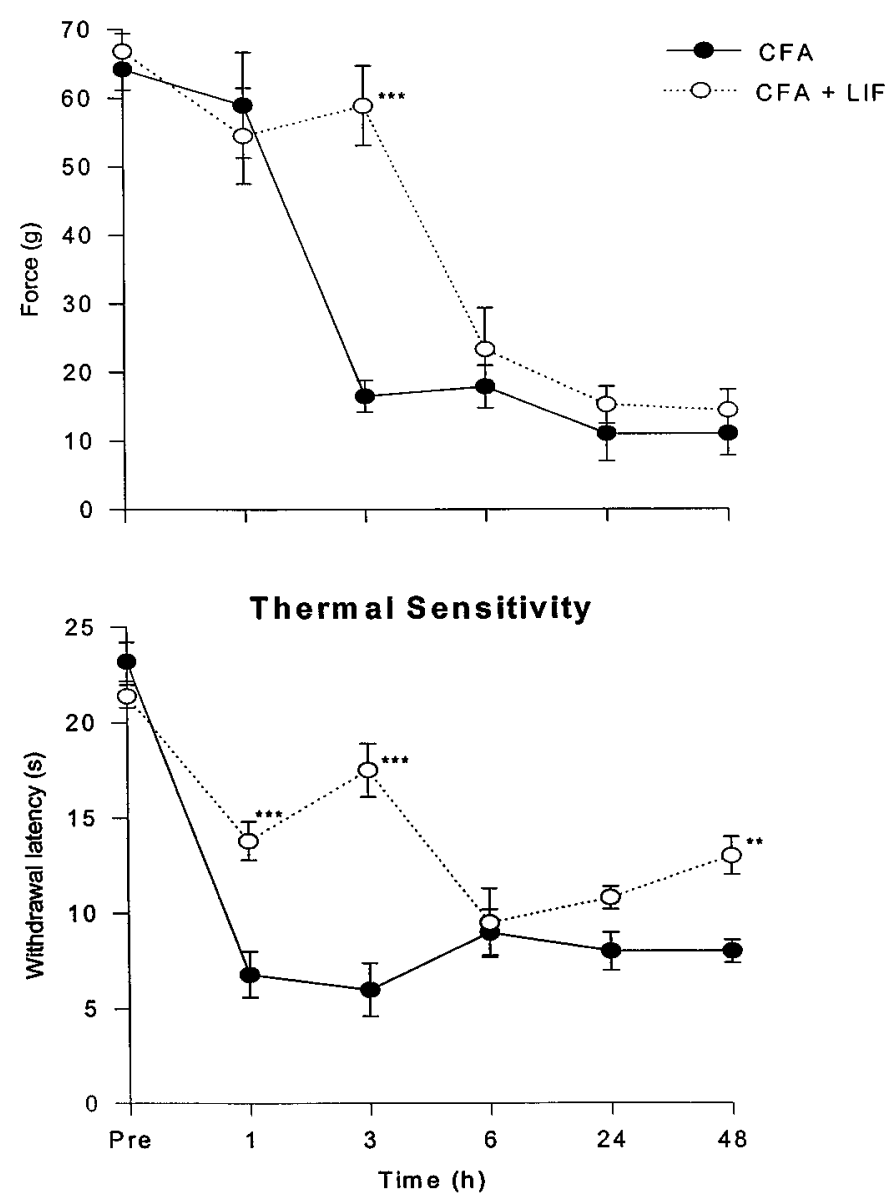

Figure 3. Administration of LIF to the paw reduces and/or delays the mechanical and thermal hypersensitivity caused by CFA. LIF (100 ng total) was injected into the plantar and dorsal surfaces of the hindpaw 10 min before CFA injection, and the sensitivity to mechanical and thermal stimuli was measured as described in Materials and Methods. Thermal hyperalgesia at 1 and $3 \mathrm{hr}$ is significantly reduced by LIF $(* * * p<0.001)$, and the difference is maintained at $48 \mathrm{hr}\left({ }^{* *} p<0.01\right)$. Mechanical sensitivity, which begins to appear at $3 \mathrm{hr}$, is also attenuated at that time $(* * *<0.001) . n=6$ for each data point.

\section{Effects of exogenous LIF}

The greater inflammatory response to CFA in mice lacking LIF suggests an anti-inflammatory role for this cytokine. To test this directly, we injected LIF into the rat hindpaw 10 min before CFA injection. Injection of $10 \mathrm{ng}$ of LIF into the hindpaw (spread over plantar and dorsal surfaces) had no detectable effect on CFAinduced inflammation, as measured by behavioral sensitivity, paw diameter, NGF, and IL- $1 \beta$ levels ( $n=5$; data not shown). Hindpaw injection of $100 \mathrm{ng}$ of LIF before CFA did, however, have a marked effect. Both mechanical and thermal sensitivity in the early phase of inflammation were substantially reduced (Fig. 3). Maximal LIF-induced analgesia in both assays was observed 3 hr after CFA injection $(p<0.001)$. An effect of LIF on thermal sensitivity was also apparent at $48 \mathrm{hr}(p<0.01)$. Thus, injection of LIF at a single time point has significant consequences for the subsequent rate and extent of pain associated with inflammation. The timing of the injection was important. In rats with preestablished CFA-induced inflammation (48 hr), injection of $100 \mathrm{ng}$ of LIF into the inflamed hindpaw failed to modify the mechanical or
Thermal Sensitivity

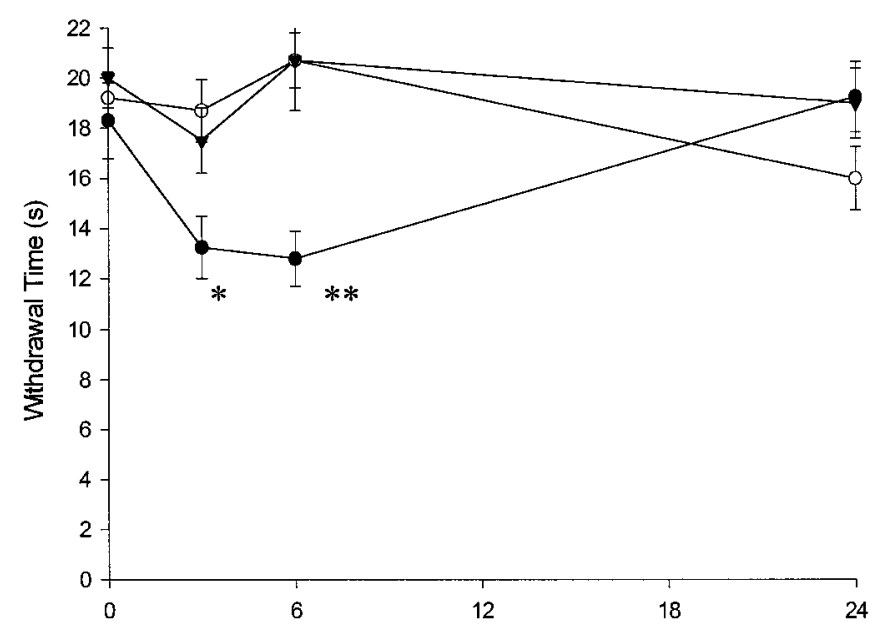

Mechanical Sensitivity

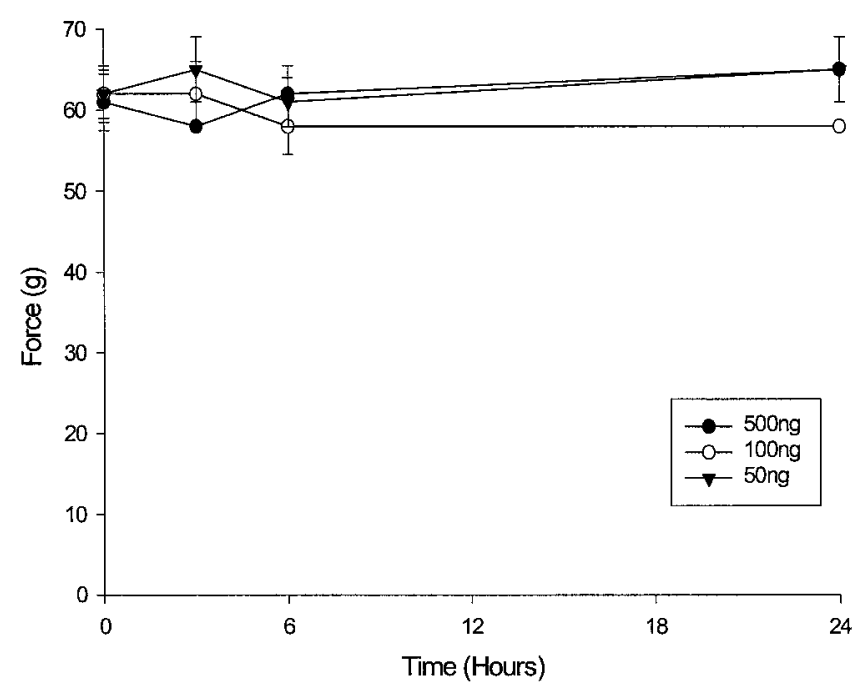

Figure 4. Intraplantar injection of LIF at 50, 100, and $500 \mathrm{ng}$ into the paw of noninflamed rats failed to modify mechanical sensitivity. The highest dose $(500 \mathrm{ng})$ did, however, significantly decrease thermal response latency at 3 and $6 \mathrm{hr}$ after injection $\left({ }^{*} p<0.05 ;{ }^{*} p<0.01\right) . n=4$ for each data point.

thermal sensitivity tested 1, 3, and $6 \mathrm{hr}$ after the LIF injections; $(n=5$; data not shown).

LIF injections at 50 and $100 \mathrm{ng}$ had little effect on baseline mechanical or thermal sensitivity in the absence of inflammation (Fig. 4), but at $500 \mathrm{ng}$ a significant thermal hyperalgesia was present 3 and $6 \mathrm{hr}$ after the high-dose injection (Fig. 4).

Consistent with its analgesic effects, LIF injection reduced the induction of IL-1 $\beta$ and NGF stimulated by CFA (Fig. 5). Injection of LIF did not, however, suppress paw swelling; $3 \mathrm{hr}$ after CFA treatment, the dorsoventral paw diameter increased by $28 \pm 6 \%$ $(n=4)$, whereas in the LIF (100 ng) + CFA group this increase was $25 \pm 4 \%(n=4)$, even though there was reduced hypersen- 

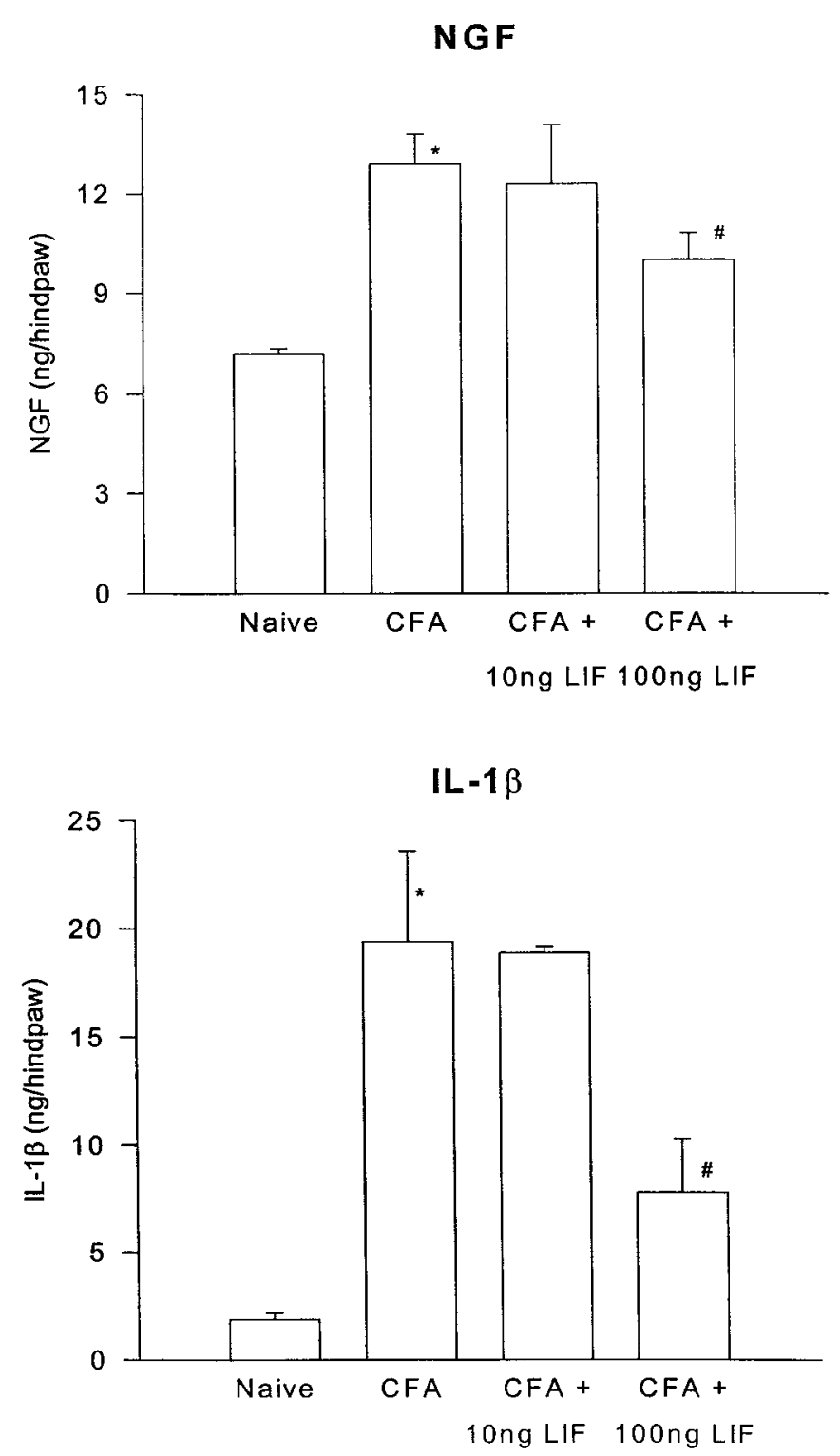

Figure 5. Intraplantar injection of LIF reduces the inflammationinduced elevation in IL-1 $\beta$ and NGF $3 \mathrm{hr}$ after CFA administration. Preadministration of $100 \mathrm{ng}$ of LIF into the plantar and dorsal surfaces of the hindpaw before CFA injection reduces the elevation in IL-1 $\beta$ levels by $60 \%$ and NGF levels by $50 \% . n=4 ;{ }^{*} p<0.05$ CFA versus naive; ${ }^{*} p<$ 0.05 CFA $+100 \mathrm{ng}$ of LIF versus CFA.

sitivity at this time. No difference in paw diameter was detected in these animals 24 and $48 \mathrm{hr}$ after CFA alone or CFA with 100 ng of LIF.

\section{DISCUSSION}

Inflammation is a complex, multifactoral process involving cell infiltration, release of cytokines, growth factors, and inflammatory mediators by inflammatory and damaged cells, as well as altered blood flow, capillary permeability, and changes in pain sensitivity (Liles and van Voorhis, 1995; Watkins et al., 1995; Dinarello, 1996). A challenge is to try to identify which signal molecules produced during inflammation directly or indirectly act on sensory neurons. Although much emphasis has been rightly placed on the sequence of changes that generate inflammatory pain hypersensitivity, it is clear that compensatory mechanisms suppressing inflammation and pain may also be recruited during and after the initial insult. Our data indicate that LIF is a major, anti-inflammatory molecule produced during cutaneous inflammation. That is, the absence of endogenous LIF leads to a large potentiation of the inflammatory response, and raising LIF levels through a single injection counters several of the acute effects of CFA.

Inflammatory edema has both neurogenic and non-neurogenic components, the latter being the consequence of the direct action of inflammatory mediators on the vasculature and capillary permeability, whereas the former are attributable to an efferent function of sensory neurons releasing vasoactive neuropeptides as part of the axon reflex (Barnes, 1996; Lynn et al., 1996). Although it is not clear which component is exaggerated in the LIF knockout mice, the failure of exogenous LIF to reduce swelling while diminishing IL-1 $\beta$ and NGF levels indicates an early divergence of the inflammatory pathways involved. This finding suggests that further investigation of LIF effects on these pathways will prove fruitful. High doses of LIF $(1 \mu \mathrm{g})$ are reported to produce swelling in the goat radiocarpal joint (Carroll et al., 1995), and injection of $>100 \mathrm{ng}$ of LIF directly into the ear pinnae of mice increases ear thickness, although by a much smaller extent than a 250 -fold lower dose of IL-1 $\alpha$ (McKenzie et al., 1996). It is possible that these proinflammatory effects of LIF are attributable to a biphasic dose dependence, such that anti-inflammatory effects are seen at lower doses. On the other had, the effects of high concentrations of LIF may be mediated through binding to receptors for other members of this cytokine family, all of which use the gp130 signal-transducing subunit (Stahl and Yancopoulos, 1994). The same issues are raised by a report that injection of a high dose $(1 \mu \mathrm{g})$ of LIF into noninflamed juvenile rats (12 d old) induces a prolonged hypersensitivity to mechanical stimulation (Thompson et al., 1996). We did not observe any effect on mechanical sensitivity with lower doses of LIF (up to $500 \mathrm{ng}$ ) in footpad injections in noninflamed adult rats. Either the dose or the age of the animals may account for this difference. We did find, though, a hyperalgesic action of LIF but only at a high dose (500 ng). Thus, caution is needed in interpreting the proinflammatory effects of high concentrations of exogenous LIF, which may have pharmacological actions that differ from those of endogenous LIF. This interpretation is supported by our results with the LIF knock-out animals.

Inflammatory pain is the consequence of changes in the sensitivity of sensory nerve endings (peripheral sensitization), as well as changes in sensory neuron phenotype and synaptic transmission in the spinal cord (central sensitization) (Woolf, 1983; Levine and Taiwo, 1994; Reeh, 1994). Multiple inflammatory mediators, including bradykinin, hydrogen ions, histamine and other amines, ATP, and prostaglandins, interact synergistically to increase transduction sensitivity of high-threshold nociceptors by phosphorylating sodium channels (Gold et al., 1996). It has recently become apparent that inflammation results in the upregulation of NGF (Donnerer et al., 1992) and that this induces peripheral sensitization by direct and indirect means (Lewin et al., 1994). NGF induction also modifies the phenotype of TrkAexpressing nociceptor neurons (Leslie et al., 1995; Neumann et al., 1996). Neutralization or sequestration of NGF has profound analgesic actions on experimental inflammation (Lewin et al., 1994; Woolf et al., 1994; McMahon et al., 1995) whereas administration of NGF induces pain hypersensitivity (Lewin et al., 1993). NGF expression during inflammation is the consequence of upregulation of both IL-1 $\beta$ and tumor necrosis factor $\alpha$ 
(TNF- $\alpha$ ) (Woolf et al., 1996, 1997). The fact that recombinant LIF suppresses both IL-1 $\beta$ and NGF upregulation after inflammation and that deletion of LIF results in an amplified induction of these proteins points to a role for LIF in regulating the cytokine cascade at an early stage. It is noteworthy that LIF appears to have different actions in chondrocytes in which it increases IL-1, IL-6, and IL-8 levels (Shimon et al., 1997). Although the cellular target for LIF action in skin remains to be determined, LIF presumably exerts its anti-inflammatory effect via the Jak-STAT pathway (Stahl and Yancopoulos, 1994). This could lead to the blockade of the transcription or release of a proinflammatory cytokine such as IL-1 (Figs. 1, 5B) or to the release of an endogenous anti-inflammatory agent such as IL-1 receptor antagonist (Dinarello, 1996). Regarding potential upstream activators of LIF, TNF- $\alpha$ induces LIF in dermal cultures (Campbell et al., 1993).

LIF mediates diverse functions in the developing and adult organism. Our findings show that LIF can be a protective cytokine, which is induced early during inflammation and which suppresses the expression of cytokines and growth factors that contribute to the inflammatory response and pain. These results suggest the opportunity for development of novel antiinflammatory and analgesic targets such as gp130 and LIF receptor agonists.

\section{REFERENCES}

Alexander HR, Billingsley KG, Block MI, Fraker DL (1994) D-factor/ leukemia inhibitory factor: evidence for its role as a mediator in acute and chronic inflammatory disease. Cytokines 6:589-596.

Baba H, Kohno T, Okamoto M, Goldstein PA, Shimoji K, Yoshimura M (1998) Muscarinic facilitation of GABA release in substantia gelatinosa of the rat spinal dorsal horn. J Physiol (Lond) 508:83-93.

Banner LR, Patterson PH (1994) Major changes in the expression of the mRNAs for $\mathrm{CDF} / \mathrm{LIF}$ and its receptor following injury to adult peripheral nerves and ganglia. Proc Natl Acad Sci USA 91:7109-7113.

Banner LR, Moayeri NN, Patterson PH (1997) Leukemia inhibitory factor is expressed in astrocytes following cortical injury. Exp Neurol 147:1-9.

Barnes PJ (1996) Neuroeffector mechanisms: the interface between inflammation and neuronal responses. J Allergy Clin Immunol 98:S73-S81.

Benigni F, Fantuzzi G, Sacco S, Sironi M, Possi P, Dinarello CA, Sipe JD, Poli V, Cappelletti M, Paonessa G, Pennica D, Panryotatos N, Ghezzi P (1996) Six different cytokines that share GP130 as a receptor subunit induce serum amyloid A and potentiate the induction of interleukin-6 and the activation of the hypothalamus-pituitary-adrenal axis by interleukin-1. Blood 87:1851-1854.

Block MI, Berg M, McNamara MJ, Norton JA, Fraker DL, Alexander HR (1993) Passive immunization of mice against D factor blocks lethality and cytokine release during endotoxemia. J Exp Med 178:1085-1090.

Brown MA, Metcalf D, Gough NM (1994) Leukemia inhibitory factor and interleukin 6 are expressed at very low levels in the normal adult mouse and are induced by inflammation. Cytokines 6:300-309.

Campbell IK, Waring P, Novak U, Hamilton JA (1993) Production of leukemia inhibitory factor by human articular chondrocytes and cartilage in response to interleukin- 1 and tumor necrosis factor $\alpha$. Arthritis Rheum 36:790-794.

Carroll GJ, Bell MC, Chapman HM, Mills JN, Robinson WF (1995) Leukemia inhibitory factor induces leukocyte infiltration and cartilage proteoglycan degradation in goat joints. J Interferon Cytokine Res 15:567-573.

Corness J, Shi T-J, Xu Z-Q, Brulet P, Hokfelt T (1996) Influence of leukemia inhibitory factor on galanin/GMAP and neuropeptide $\mathrm{Y}$ expression in mouse primary sensory neurons after axotomy. Exp Brain Res 112:79-88

Dinarello CA (1996) Biological basis for interleukin-1 in disease. Blood 87:2095-2147

Donnerer J, Schuligoi R, Stein C (1992) Increased content and transport of substance $\mathrm{P}$ and calcitonin gene-related peptide in sensory nerves innervating inflamed tissue: evidence for a regulatory function of nerve growth factor in vivo. Neuroscience 49:693-698.

Gold MS, Reichling DB, Schuster MJ, Levine JD (1996) Hyperalgesic agents increase a tetrodotoxin-resistant $\mathrm{Na}^{+}$current in nociceptors. Proc Natl Acad Sci USA 93:1108-1112.

Heyman D, L'Her E, Nguyen J-M, Raher S, Canfrere I, Coupey L, Fixe P, Chailleux S, De Grotte D, Praloran V, Godard A (1996) Leukemia inhibitory factor (LIF) production in pleural effusions: comparison with production of IL-4, IL-8, IL-10, and macrophage-colony stimulating factor (M-CSF). Cytokines 8:410-416.

Kurek JB, Austin L, Cheema SS, Bartlett PF, Murphy M (1996) Upregulation of leukemia inhibitory factor and interleukin-6 in transected sciatic nerve and muscle following denervation. Neuromuscul Disord 6:105-114.

Leslie TA, Emson PC, Dowd PM, Woolf CJ (1995) Nerve growth factor contributes to the upregulation of GAP-43 and preprotachykinin A mRNA in primary sensory neurons following peripheral inflammation. Neuroscience 67:753-761.

Levine JD, Taiwo YO (1994) Inflammatory pain. In: Textbook of Pain (Wall PD, Melzack R, eds), pp 45-56. Edinburgh: Churchill Livingstone.

Lewin GR, Ritter AM, Mendell LM (1993) Nerve growth factorinduced hyperalgesia in the neonatal and adult rat. J Neurosci 13:2136-2148.

Lewin GR, Rueff A, Mendell LM (1994) Peripheral and central mechanisms of NGF-induced hyperalgesia. Eur J Neurosci 6:1903-1912.

Liles WC, van Voorhis WC (1995) Review: nomenclature and biological significance of cytokines involved in inflammation and the host immune response. J Infect Dis 172:1573-1580.

Lotz M, Moats T, Villiger PM (1992) Leukemia inhibitory factor is expressed in cartilage and synovium and can contribute to the pathogenesis of arthritis. J Clin Invest 90:888-896.

Lynn B, Schutterle S, Pierau FK (1996) The vasodilator component of neurogenic inflammation is caused by a special subclass of heatsensitive nociceptors in the skin of the pig. J Physiol (Lond) 494:587-593.

McKenzie RC, Paglia D, Kondo S, Sauder DN (1996) A novel endogenous mediator of cutaneous inflammation: leukemia inhibitory factor. Acta Derm Venereol (Stockh) 76:111-114.

McMahon SB, Bennett DLH, Priestley JV, Shelton DL (1995) The biological effects of endogenous NGF in adult sensory neurones revealed by a trkA IgG fusion molecule. Nat Med 1:774-780.

Mehlen P, Hickey E, Weber LA, Arrigo A-P (1997) Large unphosphorylated aggregates as the active form of hsp27 which controls intracellular reactive oxygen species and glutathione levels and generates a protection against TNF $\alpha$ in NIH-3T3-ras cells. Biochem Biophys Res Commun 241:187-192.

Neumann S, Doubell TP, Leslie TA, Woolf CJ (1996) Inflammatory pain hypersensitivity mediated by phenotypic switch in myelinated primary sensory neurones. Nature 384:360-364.

Paglia D, Kondo S, Ng K-M, Sauder DN, McKenzie RC (1996) Leukemia inhibitory factor is expressed by normal human keratinocytes in vitro and in vivo. Br J Dermatol 134:817-823.

Patterson PH (1994) Leukemia inhibitory factor, a cytokine at the interface between neurobiology and immunology. Proc Natl Acad Sci USA 91:7833-7835.

Patterson PH, Kou S-Y, Sugiura S, Lahav R, Banner LR (1997) LIF coordinates neuronal and inflammatory responses to nerve injury. Soc Neurosci Abstr 23:997.

Perry GW, Burmeister DW, Grafstein B (1987) Fast axonally transported proteins in regenerating goldfish optic axons. J Neurosci 7:792-806.

Rao MS, Sun Y, Escrary JL, Perreau J, Tresser S, Patterson PH, Zigmond RE, Brulet P, Landes SL (1993) Leukemia inhibitory factor mediates an injury response but not a target-directed developmental transmitter switch in sympathetic neurons. Neuron 11:1175-1185.

Reeh PW (1994) Chemical excitation and sensitization of nociceptors. In: Cellular mechanisms of sensory processing, NATO ASI series, Cell biology, vol 79 (Urban L, ed), pp 119-131. Berlin: Springer.

Ryffel B (1993) Pathology induced by leukemia inhibitory factor. Int Rev Exp Pathol 34:69-72

Safieh-Garabedian B, Poole S, Allchorne A, Winter J, Woolf CJ (1995) Contribution of interleukin- $1 \beta$ to the inflammation-induced increase in 
nerve growth factor levels and inflammatory hyperalgesia. Br J Pharmacol 115:1265-1275.

Sendtner M, Gotz R, Holtman B, Escary J-L, Masu Y, Carroll P, Wolf E, Brem G, Brulet P, Thoenen H (1996) Cryptic physiological trophic support of motoneurons by LIF revealed by double gene targeting of CNTF and LIF. Curr Biol 6:686-694.

Shimon I, Yan X, Ray DW, Melmed S (1997) Cytokine-dependent gp130 receptor subunit regulates human fetal pituitary adrenocorticotropin hormone and growth hormone secretion. J Clin Invest 100:357-363.

Stahl N, Yancopoulos GD (1994) The tripartite CNRF receptor complex: activation and signaling involves components shared with other cytokines. J Neurobiol 25:1454-1466.

Stein C, Millan MJ, Herz A (1988) Unilateral inflammation of the hindpaw in rats as a model of prolonged noxious stimulation: alterations in behavior and nociceptive thresholds. Pharmacol Biochem Behav 31:445-451.

Stewart CL, Kaspar P, Brunet LJ, Bhatt H, Gadi I, Kontgen F, Abbondanzo SJ (1992) Blastocyst implantation depends on maternal expression of leukemia inhibitory factor. Nature 359:76-79.

Sun Y, Zigmond RE (1996) Leukemia inhibitory factor induced in the sciatic nerve after axotomy is involved in the induction of galanin in sensory neurons. Eur J Neurosci 8:2213-2220.

Szepietowski JC, McKenzie RC, Keohane SG, Walker C, Aldridge RD, Hunter JA (1997) Leukemia inhibitory factor: induction in the early phase of allergic contact dermatitis. Contact Dermatitis 36:21-57.

Thompson SWN, Dray A, Urban L (1996) Leukemia inhibitory factor induces mechanical allodynia but not thermal hyperalgesia in the juvenile rat. Neuroscience 71:1091-1094.

Ulich TR, Fann M-J, Patterson PH, Williams JH, Samal B, Del Castillo J, Yin S, Guo K, Remick DG (1994) Intratracheal injection of LPS and cytokines. V. LPS induces expression of LIF and LIF inhibits acute inflammation. Am J Physiol 267:442-446.

Waring P, Wycherley K, Cary D, Nicola N, Metcalf D (1992) Leukemia inhibitory factor levels are elevated in septic shock and various inflammatory body fluids. J Clin Invest 90:2031-2037.

Watkins LR, Maier SF, Goehler LE (1995) Immune activation: the role of proinflammatory cytokines in inflammation, illness responses and pathological pain states. Pain 63:289-302.

Weinhold B, Ruther U (1997) Interleukin-6-dependent and -independent regulation of the human $\mathrm{C}$-reactive protein gene. Biochem J 327:425-429.

Woolf CJ (1983) Evidence for a central component of postinjury pain hypersensitivity. Nature 306:686-688.

Woolf CJ, Safieh-Garabedian B, Ma Q-P, Crilly P, Winter J (1994) Nerve growth factor contributes to the generation of inflammatory sensory hypersensitivity. Neuroscience 62:327-331.

Woolf CJ, Ma Q-P, Allchorne A, Poole S (1996) Peripheral cell types contributing to the hyperalgesic action of nerve growth factor in inflammation. J Neurosci 16:2716-2723.

Woolf CJ, Allchorne A, Safieh-Garabedian B, Poole S (1997) Cytokines, nerve growth factor and inflammatory hyperalgesia: the contribution of tumor necrosis factor $\alpha$. Br J Pharmacol 121:417-424. 